\title{
Addressing Anxiety: Practitioners' Examination of Mindfulness in Constructivist Supervision
}

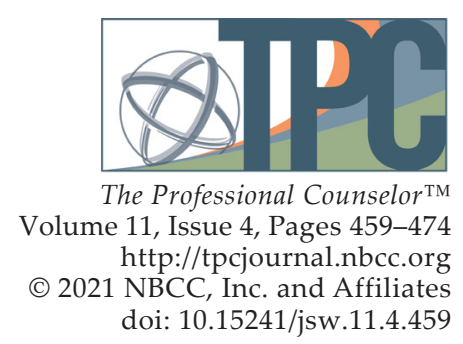

Jennifer Scaturo Watkinson, Gayle Cicero, Elizabeth Burton

It is widely documented that practicum students experience anxiety as a natural part of their counselor development. Within constructivist supervision, mindfulness exercises are used to help counselors-intraining (CITs) work with their anxiety by having them focus on their internal experiences. To inform and strengthen our practice, we engaged in a practitioner inquiry study to understand how practicum students experienced mindfulness as a central part of supervision. We analyzed 25 sandtray reflections and compared them to transcripts from two focus groups to uncover three major themes related to the student experience: (a) openness to the process, (b) reflection and self-care, and (c) attention to the doing. One key lesson learned was the importance of balancing mindfulness exercises to highlight the internal experiences related to anxiety while providing adequate opportunities for CITs to share stories and hear from peers during group supervision.

Keywords: supervision, mindfulness, counselors-in-training, anxiety, practitioner inquiry

It is widely documented that counselors-in-training (CITs) experience anxiety as part of the developmental process (Auxier et al., 2003; Kuo et al., 2016; Moss et al., 2014). Reasons for anxiety include CITs' doubts about their ability to perform competently within their professional role (Moss et al., 2014) coupled with perfectionism (Kuo et al., 2016). Additionally, Auxier et al. (2003) noted that CITs' anxiety also stems from the pressure associated with external evaluation provided by supervisors. Wagner and Hill (2015) added that CITs' need for external validation from their supervisors, coupled with the belief that there is only one right way to counsel clients, also generates anxiety. This need for external validation creates an overreliance on a supervisor's judgment that could render a CIT helpless (Wagner \& Hill, 2015). Although a moderate amount of anxiety may increase a person's focus and positively impact productivity, too much anxiety impedes learning and growth (Kuo et al., 2016). Hence, there is a need for supervisors to address anxiety early in a CIT's development to foster self-reliance and professional growth (Ellis et al., 2015; Mehr et al., 2015).

The two lead authors of this article, Jennifer Scaturo Watkinson and Gayle Cicero, are counselor educators who supervised school counseling practicum students and ascribed to a constructivist approach to supervision. While discussing supervision pedagogy, we shared our observations on how anxious our practicum students were to be evaluated and our belief that their anxiety often limited their professional growth and development as counselors. Within constructivist supervision, mindfulness exercises are used to help CITs work with their anxiety by having them focus on their internal experiences of discomfort (Guiffrida, 2015). Thus, we utilized mindfulness as a central approach to helping our students work with their anxiety associated with the counselor developmental process.

Jennifer Scaturo Watkinson, PhD, LCPC, is a certified school counselor and serves as an associate professor and the School Counseling Program Director at Loyola University Maryland. Gayle Cicero, EdD, LCPC, is a certified school counselor and serves as an assistant clinical professor at Loyola University Maryland. Elizabeth Burton is a certified professional school counselor for Baltimore County Public Schools. Correspondence may be addressed to Jennifer Watkinson, Timonium Graduate Center, 2034 Greenspring Dr., Lutherville-Timonium, MD 21093, jswatkinson@loyola.edu. 
To assist in our planning, we reviewed the supervision literature and found that discussions on mindfulness were largely conceptual (Guiffrida, 2015; Johnson et al., 2020; Schauss et al., 2017; Sturm et al., 2012) or outcome-based (Bohecker et al., 2016; Campbell \& Christopher, 2012; Carson \& Langer, 2006; Daniel et al., 2015; Dong et al., 2017), with limited focus on supervision pedagogy to guide supervisors on how to integrate mindfulness into their practicum seminars, particularly from the perspective of the practitioner. Further, Barrio Minton et al. (2014) and Brackette (2014) confirmed that there was a scarcity of counselor education literature that focused on teaching pedagogy and argued that more research in this area was needed to improve counselor preparation. To add to the current literature on supervision pedagogy and inform our practice, we engaged in a practitioner inquiry study (Cochran-Smith \& Lytle, 2009) and formed a professional learning community to investigate how utilizing mindfulness within our supervision could help school counseling practicum students work with their anxiety.

\section{Literature Review}

\section{Constructive Supervision}

Supervisors who utilize constructivist principles help CITs make meaning of their experience by examining how their approach benefits their clients (Guiffrida, 2015). Constructivism is built upon the belief that knowledge is not derived from absolute realities but rather localized to specific contexts and personal experiences. McAuliffe (2011) argued that knowledge is "continually being created through conversations" and is not given to the learner through a one-sided expert account. Constructivists believe that learning is "reflexive and includes a tolerance for ambiguity" (McAuliffe, 2011, p. 4). Constructivist supervisors prioritize CITs' experiences, encouraging them to examine the intent behind their approach and reach their own conclusions. Hence, constructive supervisors help supervisees deconstruct experiences that have multiple "right" approaches to client care while normalizing the anxiety associated with professional growth. Within a constructivist supervision framework, moderate amounts of anxiety are not viewed as problematic but rather are seen as a catalyst for change (Guiffrida, 2015) and part of the learning process (McAuliffe, 2011). Guiffrida (2015) asserted that the aim of supervision in the early stages of counselor development is not to remove feelings of anxiety but rather to help the CIT acknowledge and live with the anxiety. Utilizing mindfulness, supervisors acknowledge CITs' internal experiences and guide them through intentional mindfulness practices to generate personal and professional reflection and meaning making.

Within constructivist supervision, mindfulness is a central approach to helping CITs work with their anxiety (Guiffrida, 2015). Kabat-Zinn (2016) defined mindfulness as "paying attention in a sustained and particular way: on purpose, in the present moment and nonjudgmentally" (p. 1). Constructive supervisors facilitate learning experiences that promote introspection and intentionally direct CITs to examine their internal experience, without judgment, during times of disequilibrium. Rather than helping a CIT rid themselves of anxiety, the constructivist supervisor acknowledges that anxiety is a normal response to the uncertainty of doing something for the first time (Guiffrida, 2015). Mindfulness provides a platform for a supervisor to normalize anxiety within the supervisory relationship (Sturm et al., 2012). Hence, supervisors can utilize mindfulness to prioritize the CITs' internal experiences (e.g., doubt, uncertainty, fear) and foster self-reliance.

\section{Mindfulness as an Approach}

Mindfulness practices are linked to the personal and professional growth of CITs (Bohecker et al., 2016; Campbell \& Christopher, 2012). Campbell and Christopher (2012) compared counseling students who participated in a mindfulness-based stress reduction (MBSR) program to a control group and found 
that those who participated in MBSR reported significant decreases in stress, negative affect, rumination, and state and trait anxiety while noting a significant increase in positive affect and self-compassion when compared to participants in the control group. Additionally, Christopher and Maris (2010) reported that supervisees who were exposed to mindfulness were "more open, aware, self-accepting, and less defensive in supervision" (p. 123). Similarly, Bohecker et al. (2016) discovered that CITs who participated in a mindfulness experiential small group saw the benefits of attending to their emotions (e.g., internal experiences) and acknowledged that mindfulness increased self-awareness and promoted objectivity when attending to their thoughts. Having objectivity allowed them to be in the present, which positively affected their behavioral responses (Bohecker et al., 2016).

CITs also experienced benefits to having mindfulness incorporated into their practicum and internship seminar classes. Dong et al. (2017) examined CITs' response to mindfulness-based activities and discussions during internship seminar. Results suggested that CITs who engaged in mindfulness practices were more focused on the moment and responded to stressors with acceptance and nonjudgment. As a result, CITs were more likely to be "okay with not being okay" when faced with challenging situations (Dong et al., 2017, p. 311). Additionally, Dong and his colleagues noted that participants were able to validate themselves when they made mistakes and were more accepting of their rough edges. Carson and Langer (2006) agreed and added that CITs who received mindfulness as part of their supervision were better able to examine the thoughts that contributed to their anxiety and were more open to accepting their mistakes as learning opportunities. As a result, CITs minimized the focus they put on self-criticism and were less vulnerable when they made mistakes (Carson \& Langer, 2006). These studies highlight how CITs benefited from integrating mindfulness into group supervision, yet there is limited research on how counselor educators might structure their practicum seminars to include mindfulness as an integrated approach to supervision.

\section{Purpose of the Present Study}

The purpose of this practitioner inquiry was to inform Watkinson and Cicero's practice as supervisors of practicum school counseling students within a CACREP-accredited program. We utilized mindfulness as a central approach to group supervision during practicum seminar and wanted to understand how intentional mindfulness exercises that prioritized the CITs' internal experiences (e.g., uncertainty, doubt, fear) were perceived by our students. By understanding the student experience, we could make informed decisions about how we might improve upon the way we integrate mindfulness into future seminar meetings. Specifically, we were guided by this research question: How are CITs experiencing mindfulness as part of group supervision provided during practicum seminar?

\section{Method}

We engaged in a practitioner inquiry study (Cochran-Smith \& Lytle, 2009) to examine the application of mindfulness within the context of our practice. Cochran-Smith and Lytle (2009) argued that the examination of one's practice privileges practitioner knowledge and adds to the overall discourse on teaching pedagogy, as "deep and significant changes in practice can only be brought about by those closest to the day-to-day work of teaching and learning" (p. 6). Although not intended to generalize knowledge, practitioner inquiry positions the researcher as a participant to uncover tensions and challenges that come from applying theory to practice while enhancing the knowledge of the practitioner doing the investigation (Cochran-Smith \& Lytle, 2009). Thus, we intended to reflect upon how we integrated mindfulness into supervision by understanding the experiences of our practicum students. 


\section{Participants}

We gained approval from our university's IRB to conduct the study and invited all 33 CITs enrolled in our practicum sections to participate. Twenty-five (76\%) CITs agreed to participate. Of the 25 participants, 24 identified as female (96\%) and one identified as male (4\%). Sixteen students (64\%) self-identified as White/Caucasian, five (20\%) as African American, three (12\%) as Hispanic, and one $(4 \%)$ as other. Eighty-four percent of participants were full-time students and 16\% identified as parttime. Students were told they could withdraw their participation at any time. All practicum students completed their field experience in public schools.

To safeguard participants from believing they were required to join the study, Watkinson and Cicero were not aware of which students agreed to participate until the end of the semester, when grades were submitted. To protect participant identity until after the semester, we took the following steps: 1) the third author, Elizabeth Burton, was the only one who knew the identity of the participants; 2) Burton recruited participants, stored data (erasing identifying information), and communicated with the participants; 3 ) the data source labeled sandtray reflections included activities that all CITs completed as part of a required seminar experience; 4) a focus group was held after the semester concluded and grades were submitted; and 5) during data collection, Watkinson and Cicero never discussed the study with any of the CITs enrolled in practicum.

\section{Seminar Context}

The practicum course is the first field experience for CITs enrolled in the school counseling master's program. As per the CACREP 2016 Standards, the practicum experience is a 100-hour experience in which $40 \%$ of those hours are in direct service. In addition to meeting those direct hours by working with several individual clients, practicum students are also required to design and run a small counseling group and deliver several classroom lessons within schools. Further, CACREP-accredited programs must provide practicum students with 1.5 hours on average of group supervision per week throughout the duration of the semester. Thus, our practicum seminars were designed to provide CITs with the required group supervision.

All practicum seminar sessions met in person except for one, which was held synchronously through Zoom, a web conferencing platform. There were three sections of practicum, two taught by Cicero and one taught by Watkinson. Watkinson and Cicero drew upon constructive supervision principles and mindfulness core concepts (e.g., self-compassion, present moment, and nonjudgment) to guide the planning of the practicum seminars. We maintained similar course structures, objectives, and learning outcomes utilizing similar room arrangements, mindfulness exercises, and structured learning experiences. Mindfulness exercises were central to the practicum seminar and were focused on the practicum students' internal experiences. The 15 weekly practicum seminars were 90 minutes in length, and student-to-faculty ratios were 9:1 for two of the practicum sections and 6:1 for the third. The room arrangement consisted of a circle of chairs for students to use during the opening and closing of the seminar, along with a designated workspace for students to sit at tables to take notes or complete reflective class experiences. Soft meditation music played as students entered the room and was turned off to signal the beginning of class.

Watkinson and Cicero engaged in weekly collaborative planning meetings throughout the 15-week semester to plan their seminar meetings and share insights related to student learning. The instructional design was experiential and incorporated mindfulness exercises during the opening of the seminar to bring attention to the "here and now," breath, nonjudgment, and self-compassion. Cicero was 
previously trained in mindfulness and exercises were selected based upon her training; Cicero taught Watkinson how to implement those mindfulness exercises during their weekly meetings. Many of the opening mindfulness exercises can be found through internet searches.

\section{Structure of Seminar Meetings}

The structure and room arrangement for each practicum seminar were consistent across the three sections. Fourteen of the 15 seminar meetings began with the CITs participating in a 5-minute mindfulness opening that transitioned into structured learning experiences and ended with a sharing circle. Seminar Meeting 11 was entirely dedicated to mindfulness, engaging practicum students in several mindfulness activities for the purpose of drawing their attention to breath and reflection.

\section{Mindfulness Openings}

The 5-minute mindfulness openings were scripted and consisted of either a guided meditation (e.g., Calm Still Lake, A River Runs Through It), intentional breathing exercises (e.g., Balloon Breath, Meditative Chimes) or chair yoga (e.g., Mountain Pose, Warrior 2). Each mindfulness opening concluded with reflective questions to increase awareness of the present moment (e.g., What was this experience like for you?). The meditation exercises were varied to introduce CITs to different approaches they might want to try outside of seminar for personal use or in their own practice with $\mathrm{K}-12$ students.

\section{Structured Learning Experiences}

After the mindfulness opening, CITs participated in structured learning experiences that focused on either counselor development, case conceptualization, group counseling leadership, evidencebased planning, or classroom curriculum development and instruction. Guided by constructivist supervision principles, two of the structured learning experiences implemented were metaphorical case drawing (Guiffrida, 2015) and sandtray (Guiffrida, 2015; Saltis et al., 2019).

Metaphorical Case Drawing. Guiffrida's (2015) metaphorical case drawing was used to assist CITs in the development of their case conceptualization skills. In Guiffrida's work, a metaphorical case drawing has three steps. First, CITs reflect upon six items that highlight their internal experiences and perspectives specific to an individual counseling session with one of their clients: 1) identification of the client's primary concern, 2) description of the client and CIT interaction, 3) CIT's intention for the session, 4) CIT's description of how they viewed their performance as a counselor during the session, 5) general assessment of how the session went, and 6) statement on what the CIT thought the client gained from the session. Second, CITs use images and/or metaphors to respond to three of the six items above to create a case drawing. Lastly, utilizing their case drawings, CITs share their cases with the supervisor and other supervisees. Through the presentation of their case, the CITs interpreted their work while the supervisor and other supervisees listened and asked questions to facilitate deeper insight by offering alternative perspectives.

Sandtray. Although sandtray is typically used in supervision to help CITs develop their case conceptualization skills (Anekstein et al., 2014; Guiffrida, 2015; Guiffrida et al., 2007), we modified our use of sandtray to focus the CITs on their developmental journey as counselors. Like the metaphorical case drawing, the sand tray facilitates an internal examination where CITs get to interpret their own experience (Guiffrida et al., 2007). The sandtray was used in Seminar Meetings 6 and 13 to document how CITs were encountering practicum at two different times in the semester. The written reflections that followed the sandtray were used as a data source for this study and are therefore described in further detail. 
Prior to creating an image in the sandtray, CITs were asked to journal about their experience as a practicum student. The prompt was left open so that CITs would have the freedom to focus on the most salient part of their experience. Next, CITs were partnered to create a sand tray image and each pair were given a large box that contained sand and a small baggie filled with a variety of miniature objects. CITs had 5 minutes to create an image in response to this prompt: Create an image that represents your practicum experience thus far. At the conclusion of the 5 minutes, CITs shared their stories with their partners. After everyone created a sandtray image and shared, CITs wrote a reflection in response to this prompt: Drawing from the sandtray exercise and sharing, describe your experience in practicum thus far. Identify and describe the thoughts and feelings you have as you begin your work with students. These written reflections were submitted to the professor at the conclusion of the seminar meeting.

At Seminar Meeting 13, CITs created and shared their sandtray images. Following the same procedure as identified in Seminar Meeting 6, CITs engaged in the sandtray activity again to create a new image in response to a new prompt: Create an image that described your overall experience in practicum. After creating and sharing of their image with a partner, students reflected and responded in writing to a final prompt: Drawing from the sandtray exercise, describe your experience in practicum. Identify and describe your thoughts and feelings now that practicum has come to an end. What have you learned about yourself? Written reflections were completed during the seminar meeting and submitted to the professor when class ended.

\section{Sharing Circle}

After the structured learning experience, each seminar concluded with a 5-10 minute sharing circle where students summarized new insights and identified actions to implement at their practicum site. The sharing circle was guided by two questions: What are some key takeaways from today's seminar? and How might we use what we have learned today within our own practice?

\section{Structure of Mindfulness Seminar Meeting}

Seminar Meeting 11 was fully dedicated to the practice of mindfulness and did not follow the above seminar format and structure. During this one 90-minute class, CITs identified an intention, created a mindfulness jar, journaled, and walked a labyrinth. Johnson et al. (2020) argued that CITs who receive mindfulness as part of their supervision should start or maintain a mindfulness practice of their own. Yet there is nothing in the research that identifies specific mindfulness exercises as being essential to that practice, only that CITs should be exposed to mindfulness as part of the classroom experience (Johnson et al., 2020). Thus, our intent for this seminar meeting was to engage CITs in mindfulness exercises that would encourage meditation and reflection. For this class we requested a large room to accommodate a small circle arrangement of 10 chairs and three stations: a labyrinth, creating a mindfulness jar, and journaling. During this seminar meeting, the CITs were instructed to visit the three stations at their own pace and to self-select the order in which they participated in those stations. Class opened with a mindfulness exercise that focused on breath and ended with a sharing circle to debrief. An example of a closing question posed by the professors during the sharing circle is: What insights would you like to share about your experience in seminar today?

Labyrinth. CITs were given a brief description of a labyrinth along with written instructions on how to set an intention and walk the labyrinth. We created a floor labyrinth for use during the seminar. CITs set their intention prior to walking the labyrinth. Some examples of intentions were to be open to the process or to demonstrate self-compassion. Once inside the labyrinth, CITs would follow the path and could walk the labyrinth as many times as they desired. 
Creating Mindfulness Jars. CITs created a mindfulness jar from an empty 8-ounce bottle, fine glitter, clear hand soap, confetti, and water. Directions on how to create a mindfulness jar were provided at the station. CITs were encouraged to use the mindfulness jar during the 90-minute seminar as a focal point to guide their breath during reflection time.

Journaling. CITs were provided paper, pens, markers, and crayons for journaling at the beginning of the seminar. CITs were provided minimal directions on what they were to journal, outside of selecting a quiet place in the room to write and reflect upon their experience during the session. Journals were private and CITs were not asked to share what they wrote with the professors or other CITs.

\section{Data Sources and Collection}

We used three data sources to understand CITs' experience with mindfulness as part of supervision: supervisor observations, sandtray reflections from weeks 6 and 13, and focus group transcripts. Watkinson and Cicero captured supervisor observations in their meeting minutes, which also included specific plans for each seminar session along with assumptions and observations about CIT learning. The written sand tray reflections captured CITs' overall experience in practicum at two different points in the semester. Using a multi-step process, the sandtray served as a structured learning experience completed and collected during the seminar meetings. Data from sandtray reflections taken at the end of the semester (week 13) were analyzed to examine how CITs reflected on their overall practicum experience at the completion of the semester.

All 25 participating CITs were invited to participate in a focus group. Of the 25, nine (36\%) attended and two different focus groups were held to accommodate their schedules. Each focus group was held virtually on Zoom, recorded, and transcribed, and took place at the end of the academic semester after grades were issued. Focus groups lasted 60 minutes, were co-led by Watkinson and Cicero, and served as a type of member checking. Guiding questions/prompts were: Describe your experience in practicum this semester, Describe your feelings throughout the semester, and What was it like for you to engage in mindfulness as part of your development as a counselor?

\section{Trustworthiness}

Watkinson and Cicero are both counselor educators at a university located within the Mid-Atlantic region of the United States. Watkinson is a Caucasian middle-aged female with 14 years of experience as a school counselor and over 10 years of experience as a counselor educator. Cicero is a Caucasian middleaged female with 30 years of experience in a large public school district as a teacher, school counselor, and a district-level administrator of school counseling and student service programs, as well as 3 years of experience as a counselor educator. Watkinson and Cicero are licensed professional counselors, board approved certified supervisors, and certified school counselors. Burton was a first-semester school counseling student and served as Watkinson's graduate assistant. She is a Caucasian female with no prior experience in schools or as a counselor. At the time of data analysis, she had finished her first year of coursework and offered an additional perspective on how the data could be interpreted.

Watkinson and Cicero held certain biases and assumptions about how mindfulness might be experienced by CITs in their practicum sections. We assumed that mindfulness was beneficial to CIT counselor development yet had no preconceived ideas as to the type of benefit it would have on their professional growth outside of our assumption that mindfulness could help CITs work with their anxiety. Additionally, we found that CITs, particularly at the practicum level, were anxious and 
worried about their performance and believed that supervision was needed to attend to that anxiety. Lastly, we shared a strong desire to better understand our own practice and were therefore open and expected feedback to strengthen that practice.

Trustworthiness was addressed in a variety of ways. In practitioner research, validation is obtained through a form of peer review, where practitioner researchers collaborate to discuss and reflect upon their experiences through peer feedback (Anderson \& Herr, 1999; Cochran-Smith \& Lytle, 2009). Thus, Watkinson and Cicero met weekly during the 15-week semester to share observations and obtain feedback related to their own practice. Further, during these meetings we engaged in critical dialogue to disrupt previously held assumptions and biases. For example, we challenged each other to share evidence to support the interpretations we made about how students were experiencing the course, asking the question, How do you know? Observations that included peer feedback were recorded in our meeting minutes.

Second, we engaged in prolonged observation of participants as we worked alongside CITs, acting in the role of both inside and outside observers during the 15-week semester. As Creswell (2013) asserted, validation of findings comes from prolonged engagement and persistent observation of participants. Third, we triangulated data, comparing Seminar Meeting 13 sandtray reflection data across the three practicum sections to the focus group transcripts (Merriam, 2009). Fourth, the focus groups served as a type of member checking (Merriam, 2009) to validate and refine our analysis of the final sandtray reflections to the perceptions that were shared by students in the focus groups.

\section{Data Analysis}

We formed a research team and regularly met to debate and discuss the data during the analysis process. Data from the sandtray reflections taken during Seminar Meeting 13 were organized into a table for analysis so that we could track individual responses and practicum sections. Drawing from Creswell's (2013) process for analyzing data, we each familiarized ourselves with the data by independently engaging in multiple readings of the final sandtray reflections and focus group transcripts, including memoing to capture initial impressions and key concepts. After familiarizing ourselves with the data, we met as a research team to share initial insights and bracket assumptions. Next, we reviewed each line of the final sandtray reflection data independently to identify initial codes. As a research team, we shared our codes, discussed discrepancies, and reviewed units of data until consensus was reached and a codebook was created. Next, codes from the final sandtray reflections were compared to the focus group transcripts and refined. Lastly, we looked for patterns in the data and organized them into themes.

\section{Findings}

To examine our supervision practice, we sought to understand how CITs experienced mindfulness as a supervision approach. Prioritizing mindfulness within our practicum seminar meetings focused our students on the examination and understanding of their internal experiences and meeting uncertainty with nonjudgment and self-compassion. After analyzing the data, three major themes emerged: openness to the process of becoming, reflection and self-care, and attention to the doing.

\section{Openness to the Process of Becoming}

Although CITs acknowledged the challenges associated with their experience, they also expressed an openness to becoming a counselor who generated personal insight, self-compassion, and wisdom. As one participant stated, "It's natural to feel uncertain when learning new concepts. However, 
uncertainty should not consume you and cause your thoughts to become negative. Give yourself permission to grow." Another wrote, "The biggest growth I've seen in myself is self-awareness. Regardless of my weaknesses and shortcomings, I am good enough!! The greatest gift I can give to students is to be myself."

CITs felt hopeful and purposeful in their development as counselors and expressed excitement about their professional growth. As one participant remarked, "In the beginning everything seemed new and scary, but when I look at the end, I see so much growth. I will continue to grow and expand. I look forward to my career." Another wrote:

At the beginning of practicum, I felt awkward and unsure of myself. I felt selfconscious. At the end of practicum, I can feel the growth I've made. I no longer feel awkward or self-conscious. I know who I am and what kind of counselor I am.

Acknowledging the emotional challenges of their professional journey, CITs highlighted the emotional discomfort they felt at the start of practicum. One student stated: "Anxiety from the beginning - feeling of anxiety and not knowing what to expect." Another mentioned in her reflection, "I definitely had feelings of inadequacy. I just didn't think that I was doing what I needed to do." Some students expressed this discomfort as cyclical:

Understanding everything that was going to be happening and everything that was expected and what it all entails, I definitely started to get more anxious and got comfortable and then getting [anxious] again. So, kind of like back and forth a lot.

Students compared this back and forth feeling to that of a rollercoaster: "I feel like some weeks I'd be on fire, like, yeah, I did really good ... there would be other days where it's like my timing is off and I'm uncomfortable in the classrooms ... it was definitely a rollercoaster feeling."

Another student agreed, sharing that they "would definitely second the rollercoaster. The beginning was very overwhelming for sure ... that rollercoaster of like the expectation of learning ... feeling like you're doing really bad and then learning what is good."

There was also a sense of wisdom in how the participants described what they gained from this experience of becoming. One participant mentioned "feeling depressed and anxious.... Fast forward 2 months and I had grown so much. I can't believe in only 60 days my attitude toward practicum changed so dramatically. ... change and growth take time, but it does happen." Another CIT stated:

In my first reflection, there seemed to be a lot of low points, but I was hopeful things would get better. In my second reflection, I realized that the things I have done have made an impact and the highs and lows both got me to this point.

CITs expressed recognition of the highs and lows experienced and within that recognition focused on a greater purpose. As one wrote,

I started out being very unaware and doubtful of myself. I was overwhelmed and wasn't seeing the beauty in the process of learning who I am as a counselor. I began to see the small and big impacts that I had with my students in 15 weeks. I saw the power that comes with being a counselor and am more mindful of the impact I have and will make. 
Another reflected:

The biggest growth I've seen in myself is self-awareness. Awareness of my strengths and weaknesses so that I can be mindful of how to be the best I can be for all students. So that I can strive to have a positive impact on others.

Another mentioned:

At this point in the journey, I finally met my passion. I always wanted to have an impact not because I taught a great lesson, but because I helped a student and showed I cared. I grew by knowing how to use my tools to make a difference while finding my style of counseling in the process. The growth hasn't stopped and needs refinement, but I want each day to be better for myself and the students.

Additionally, CITs perceived feedback to be essential to their growth process. One CIT reflected that they "learned to be open to change ... accepting feedback and letting it help me make positive changes throughout this journey. There is always a need for continued growth and development." Another remarked:

I've realized that in order for me to learn and grow I have to be more open [to feedback]. Being closed off means that I am only working with what I know, which is not helpful to me personally, but also what we tell students not to do. Being open has forced me to become a more active participant in my learning and take more risks ... it will all be worth it in the end.

Another practicum student focused on gratitude:

Feedback and supervision helped to change my perspective and boost my confidence. Things about myself that I thought had nothing to do with being a counselor were highlighted and the areas for improvement were spoken of and tended to with genuine care. I'm grateful to have had the experience of becoming so reflective. I'm grateful for the lows and the moments where I felt as though I was at a standstill. I'm grateful for falling so hard that my only option was to reach out and ask for help. I'm grateful for the hurdles ... and I'm grateful for the ever-flowing river. I'm grateful for the art and the science of counseling. I'm grateful for who I'm becoming in the process of becoming. I'm grateful for grace and for the realization of how necessary it is. I'm grateful for family and adopted big sisters in the program. I'm grateful to have had the chance to say "I don't know" and keep learning.

The theme of openness to the journey was also highlighted in the acknowledgement of not being in control. There was an openness to embracing the unknown and the chaos associated with not having everything figured out, as one CIT concluded:

In the beginning, I was working really hard to try to figure everything out. I saw obstacles everywhere. As I moved on, I started to focus on counseling in a way that didn't put pressure on me to do all of the right things. I started to grasp the essence of counseling and what makes the profession unique. 
Another noted:

One major insight is that it was a chaotic journey. It's not straightforward, and I don't always know the path I'll take, but I am continuously growing and learning about myself as a person and as a school counselor. ... I am enjoying the unknown. I like what I am doing, and I like moving forward, even if I am unsure at times.

\section{Reflection and Self-Care}

CITs reported that the seminar was very reflective, which gave them a sense of calm and a new appreciation for self-care. As one student commented, "I did, like everyone else, find [the seminar class] to be calming, enjoyable, and reflective." Reflection generated by the mindfulness exercises gave CITs an opportunity to get to know themselves:

It was definitely a positive experience for sure. I would agree it was very calming and super reflective. I felt like I understood myself as a counselor and also just like as a person on my own personal journey. Even aside from that I felt like I learned a lot.

Further, CITs expressed the importance of reflection and giving themselves the space to be in the present moment as a means of self-care:

I am so wrapped up in everything that is going on in my life and getting everything done. And school takes a lot of everything I've got ... to be reminded and practice [mindfulness] on a regular basis ... but doing it each week in class, helped me to do it at home. So that was giving me that practice and repetition and it really made a huge difference.

Another mentioned, “There's just so many things going on in your life ... to be reflective and just calm my inner self and learn how to breathe ... this was a life skill class for me," and a different student elaborated, "I was so grateful for it because I realized how much self-reflection I have to do ... that I need to keep doing it and making it a priority."

\section{Attention to the Doing}

Although students valued the priority that we placed upon mindfulness to better understand their internal experiences, some wished that we had provided more time for them to share stories about their practicum sites. As one CIT stated, "I would have liked to have had time each week for all of us to share what was going on and to learn from each other's situations and to support each other in those situations." Additionally, CITs desired to know more about what was happening at different practicum sites because of the belief that they were missing an experience. As one CIT explained, "I didn't have a role model so it was nice to hear everyone else's role models ... so I could just learn from pieces I wasn't getting [at my site]." Another CIT agreed: "I think it definitely would have helped to hear more about other people's sites just because I wasn't really getting a ton out of my site. Or I did get things, but differently." Another mentioned, "I wanted to hear other people's experiences because I felt like everyone was at such different schools and different levels ... we're all experiencing different things." 


\section{Discussion}

We sought to understand how practicum students experienced mindfulness exercises within supervision to improve our own practice. To help practicum students work with their anxiety, mindfulness exercises were heavily integrated into the course structure to engage all CITs in weekly reflective exercises that directed their attention toward their internal experiences. Practicum students were invited to acknowledge their anxiety and respond to it with nonjudgment and self-compassion. Mindfulness core concepts (e.g., being present, nonjudgment, self-compassion) served as a framework for how practicum students made meaning of their internal experiences. Although our focus was not to determine the impact mindfulness had on our practicum students, to inform our practice we did seek to gain a descriptive understanding of how our students experienced mindfulness as part of their group supervision.

\section{Open to the Process of Becoming}

Our CITs reported being open to the process of becoming a counselor that included acceptance of where they were in the developmental process. Through acceptance, CITs reported being aware of the uncertainty associated with learning a new skill and leaned into that anxiety with self-compassion and nonjudgment. Further, they were able to acknowledge the ambiguity (e.g., "rollercoaster") associated with learning something new and the tension that comes with being uncomfortable. Bohecker et al. (2016) found similar results in their qualitative study, acknowledging that CITs who integrated mindfulness practices into their daily lives were better able to handle the ambiguity associated with counselor development. As part of her correlational study, Fulton (2016) found that self-compassion, a core principle of mindfulness, was predictive of a CIT's tolerance to handle ambiguity. Thus, our findings support and add to the current literature by describing qualitatively how practicum students made meaning of that uncertainty to normalize the tension that was associated with it.

\section{Self-Care}

Participants saw reflection as a form of self-care, finding meditation to be relaxing, and they acknowledged that meditating each week during seminar allowed them to stay in the present moment. Similarly, Duffy and colleagues (2017) found that CITs in their qualitative study who participated in weekly mindfulness exercises as part of a core class described mindfulness as reflective, providing them with a sense of calm and ability to stay within the present. Banker and Goldenson (2021) noted that CITs within their qualitative study also reported personal benefits to utilizing mindfulness within their practicum seminar, including being able to better transition to the present moment. Thus, the experiences our practicum students had connecting reflection as a form of self-care are similar to the experiences of other CITs who practiced regular meditation.

\section{Attention to the Doing}

Although CITs saw value in participating in group supervision that integrated mindfulness as a central approach within their practicum seminars, some CITs wanted more focus on learning about the experiences other practicum students had at their school sites. Specifically, CITs desired to know more about school counselor practice by sharing stories of what their peers were doing, as well as the work being done by the practicing school counselor. Participants sought more understanding on school counselor practice either because of a lack of modeling at their own schools or professional curiosity. Similarly, Watkinson et al. (2018) noted that counselor educators reported discrepancies between how school counseling CITs were being prepared versus what they experienced in the field. For example, counselor educators shared that they often taught content (e.g., implementing a 
comprehensive school counseling program) that their school counseling CITs did not see modeled at their schools. Thus, it would seem logical that CITs at the practicum level would want to have more exposure to activities that school counselors were doing at other sites, especially if what they were observing was not aligned with their training.

\section{Reflecting on Our Own Practice: Lessons Learned}

Through this practitioner inquiry, we gained some valuable insight into how CITs experienced mindfulness that has informed our practice. First, by analyzing our CITs' experiences in practicum, we believed that they benefited from the mindfulness exercises as a way to work with their anxiety. Specifically, we were encouraged that practicum students expressed an openness to the process of becoming a counselor, which included self-acceptance. CITs stated they were more open to feedback and less critical of themselves, recognizing they still had much to learn. Second, we learned that although the integration of mindfulness as a central approach to our supervision could be helpful to practicum students, CITs also expressed a desire to have more time dedicated to hearing about the work their peers and other practicing school counselors were doing within schools. This was particularly important if the CIT believed their site was lacking. Hence, as supervisors we needed to create a balance between engaging our CITs in mindfulness practices and the need that our CITs had to share work stories and gain some practical insight into the work of school counselors.

Cochran-Smith and Lytle (2009) highlighted that a benefit to practitioner inquiry was the uncovering of professional dilemmas that naturally occur when you apply a concept to practice. For us, seeking balance challenged us to consider what specific mindfulness exercises were critical to maintain. Watkinson et al. (2018) also found that counselor educators struggled with balancing the amount of content that needs to be covered in a course versus the depth of understanding that is needed for CITs to apply the content learned. Thus, we too needed to decide on depth versus breadth, which boiled down to identifying the frequency with which we had our practicum students participate in mindfulness exercises in each seminar meeting to gain benefit.

Because the recent literature suggested that exposure to weekly mindfulness exercises within core courses and clinical seminars benefited CITs (Campbell \& Christopher, 2012; Dong et al., 2017; Fulton, 2016), we decided to keep the opening mindfulness meditative exercises and remove the one seminar session we had dedicated to mindfulness. Further, we increased the time CITs spent in sharing circles to include space for CITs to talk about the work being done by school counselors (or themselves) at practicum sites. Lastly, we looked for opportunities to highlight mindfulness principles in case conceptualization.

To integrate mindfulness principles into case conceptualization, Sturm and colleagues (2012) proposed using metaphors (i.e., Earth, Air, Water, Space and Fire) that represent ancient Buddhist principles when conceptualizing cases. For instance, the Earth metaphor symbolizes grounding, and when applied to case conceptualization enables CITs to consider what grounds them personally and theoretically when treating a client (Sturm et al., 2012). Another example of integrating core mindfulness principles into supervision is through free association (Schauss et al., 2017). Schauss et al. (2017) used free association to help CITs attend to the present by asking questions that focused CITs on the here and now (Schauss et al., 2017). Sample questions include: What are you feeling in this moment? When and in what ways has this feeling surfaced during your counseling experiences at your school site? How does your body respond to this type of feeling and what is the impact on your counseling experiences? By integrating mindfulness principles into skill development (e.g., case conceptualization), our practicum students would be further exposed to core mindfulness principles. 


\section{Limitations and Future Research}

Our intention of sharing the findings from this study was to offer a practitioner's perspective on how CITs experienced mindfulness within supervision to contribute to the broader discussions on counselor education pedagogy. Generalization was not the objective, and findings need to be interpreted within the context of practice. Further, this study did not examine the impact that mindfulness had on CIT anxiety, and we are not able to infer such causal relationships. To strengthen our understanding of counselor education pedagogy, future studies could build upon our findings to identify which mindfulness exercises had the greatest impact on helping CITs work with their anxiety. Understanding which mindfulness exercises impact anxiety, counselor educators could be more intentional with the exercises they include, thus making room for other supervision priorities (e.g., CITs hearing about the work of practicing school counselors).

Future research could also investigate how supervisors' modeling of core mindfulness principles could impact counselor development and the supervisory alliance. Daniel et al. (2015) have called upon researchers to increase understanding of how supervisors' mindfulness behaviors impact the supervisory relationship. Future research could attend to this deficiency within the literature by looking at the relationship between a supervisor's mindfulness behaviors and the supervisory relationship through a practitioner lens.

\section{Conclusion}

By incorporating a mindfulness approach into supervision, we learned that CITs were open to working with the anxiety associated with becoming a counselor. This openness or self-acceptance gave them the perspective to appreciate the impact this experience had on them and others while also valuing the benefits of reflection through meditation. The intent of this study was not to generalize the experience of these CITs to others; rather, it was to generate conversation and an understanding of how CITs experienced mindfulness to better our practice as supervisors. Although CITs saw benefits of mindfulness within supervision, they also desired more conversations on counselor practice to better their understanding of the role school counselors have in schools. As supervisors, we understand mindfulness should be balanced with the need for CITs to learn about the work of the school counselor through the sharing of experiences at their practicum sites. Beginning each session with a mindfulness exercise and infusing mindfulness core principles into case conceptualization could be a means to achieve such balance.

\section{Conflict of Interest and Funding Disclosure}

The authors reported no conflict of interest or funding contributions for the development of this manuscript. 
The Professional Counselor I Volume 11, Issue 4

\section{References}

Anderson, G. L., \& Herr, K. (1999). The new paradigm wars: Is there room for rigorous practitioner knowledge in schools and universities? Educational Researcher, 28(5), 12-21. https://www.jstor.org/stable/1176368

Anekstein, A. M., Hoskins, W. J., Astramovich, R. L., Garner, D., \& Terry, J. (2014). Sandtray supervision: Integrating models and sandtray therapy. Journal of Creativity in Mental Health, 9(1), 122-134. https://doi.org/10.1080/15401383.2014.876885

Auxier, C. R., Hughes, F. R., \& Kline, W. B. (2003). Identity development in counselors-in-training. Counselor Education and Supervision, 43(1), 25-38. https://doi.org/10.1002/j.1556-6978.2003.tb01827.x

Banker, J. E., \& Goldenson, D. (2021). Mindfulness practices in supervision: Training counselors' experiences. The Family Journal, 29(1), 17-23. https://doi.org/10.1177/1066480720954204

Barrio Minton, C. A., Wachter Morris, C. A., \& Yaites, L. D. (2014). Pedagogy in counselor education: A 10-year content analysis of journals. Counselor Education and Supervision, 53(3), 162-177. https://doi.org/10.1002/j.1556-6978.2014.00055.x

Bohecker, L., Vereen, L. G., Wells, P. C., \& Wathen, C. C. (2016). A mindfulness experiential small group to help students tolerate ambiguity. Counselor Education and Supervision, 55(1), 16-30. https://doi.org/10.1002/ceas.12030

Brackette, C. M. (2014). The scholarship of teaching and learning in clinical mental health counseling. New Directions for Teaching and Learning, 2014(139), 37-48. https://doi.org/10.1002/tl.20103

Campbell, J., \& Christopher, J. (2012). Teaching mindfulness to create effective counselors. Journal of Mental Health Counseling, 34(3), 213-226. https://doi.org/10.17744/mehc.34.3.j756585201572581

Carson, S. H., \& Langer, E. J. (2006). Mindfulness and self-acceptance. Journal of Rational-Emotive and CognitiveBehavior Therapy, 24(1), 29-43. https://doi.org/10.1007/s10942-006-0022-5

Christopher, J. C., \& Maris, J. A. (2010). Integrating mindfulness as self-care into counselling and psychotherapy training. Counselling and Psychotherapy Research, 10(2), 114-125. https://doi.org/10.1080/14733141003750285

Cochran-Smith, M., \& Lytle, S. L. (2009). Inquiry as stance: Practitioner research for the next generation. Teachers College Press.

Creswell, J. W. (2013). Qualitative inquiry \& research design: Choosing among five approaches. (3rd ed.). SAGE.

Daniel, L., Borders, L. D., \& Willse, J. (2015). The role of supervisors' and supervisees' mindfulness in clinical supervision. Counselor Education and Supervision, 54(3), 221-232. https://doi.org/10.1002/ceas.12015

Dong, S., Campbell, A., \& Vance, S. (2017). Examining the facilitating role of mindfulness on professional identity development among counselors-in-training: A qualitative approach. The Professional Counselor, 7(4), 305-317. https://doi.org/10.15241/sd.7.4.305

Duffy, J. T., Guiffrida, D. A, Araneda, M. E., Tetenov, S. M. R., \& Fitzgibbons, S. C. (2017). A qualitative study of the experiences of counseling students who participate in mindfulness-based activities in a counseling theory and practice course. International Journal for the Advancement of Counselling, 39(1), $28-42$. https://doi.org/10.1007/s10447-016-9280-9

Ellis, M. V., Hutman, H., \& Chapin, J. (2015). Reducing supervisee anxiety: Effects of a role induction intervention for clinical supervision. Journal of Counseling Psychology, 62(4), 608-620. https://doi.org/10.1037/cou0000099

Fulton, C. L. (2016). Mindfulness, self-compassion, and counselor characteristics and session variables. Journal of Mental Health Counseling, 38(4), 360-374. https://doi.org/10.17744/mehc.38.4.06

Guiffrida, D. A. (2015). Constructive clinical supervision in counseling and psychotherapy. Routledge.

Guiffrida, D. A., Jordan, R., Saiz, S., \& Barnes, K. L. (2007). The use of metaphor in clinical supervision. Journal of Counseling \& Development, 85(4), 393-400. https://doi.org/10.1002/j.1556-6678.2007.tb00607.x

Johnson, D. A., Ivers, N. N., Avera, J. A., \& Frazee, M. (2020). Supervision guidelines for fostering statemindfulness among supervisees. The Clinical Supervisor, 39(1), 128-145. https://doi.org/10.1080/07325223.2019.1674761

Kabat-Zinn, J. (2016). Mindfulness for beginners: Reclaiming the present moment-and your life. Sounds True, Inc.

Kuo, H.-J., Landon, T. J., Connor, A., \& Chen, R. K. (2016). Managing anxiety in clinical supervision. Journal of Rehabilitation, 82(3), 18-27. 
McAuliffe, G. (2011). Constructing counselor education. In G. McAuliffe \& K. Eriksen (Eds.), Handbook of counselor preparation: Constructivist, developmental, and experiential approaches (pp. 3-12). SAGE.

Mehr, K. E., Ladany, N., \& Caskie, G. I. L. (2015). Factors influencing trainee willingness to disclose in supervision. Training and Education in Professional Psychology, 9(1), 44-51. https://doi.org/10.1037/tep0000028

Merriam, S. B. (2009). Qualitative research: A guide to design and implementation (3rd ed.). Jossey-Bass.

Moss, J. M., Gibson, D. M., \& Dollarhide, C. T. (2014). Professional identity development: A grounded theory of transformational tasks of counselors. Journal of Counseling $\mathcal{E}$ Development, 92(1), 3-12. https://doi.org/10.1002/j.1556-6676.2014.00124.x

Saltis, M. N., Critchlow, C., \& Smith, J. A. (2019). Teaching through sand: Creative applications of sandtray within constructivist pedagogy. Journal of Creativity in Mental Health, 14(3), 381-390. https://doi.org/10.1080/15401383.2019.1624995

Schauss, E., Steinruck, R. E., \& Brown, M. H. (2017). Mindfulness and free association for multicultural competence: A model for clinical group supervision. Journal of Counselor Practice, 8(2), 102-119. https://doi.org/10.22229/xpw610283

Sturm, D. C., Presbury, J., \& Echterling, L. G. (2012). The elements: A model of mindful supervision. Journal of Creativity in Mental Health, 7(3), 222-232. https://doi.org/10.1080/15401383.2012.711718

Wagner, H. H., \& Hill, N. R. (2015). Becoming counselors through growth and learning: The entry transition process. Counselor Education and Supervision, 54(3), 189-202. https://doi.org/10.1002/ceas.12013

Watkinson, J. S., Goodman-Scott, E. C., Martin, I., \& Biles, K. (2018). Counselor educators' experiences preparing preservice school counselors: A phenomenological study. Counselor Education and Supervision, 57(3), 178-193. https://doi.org/10.1002/ceas.12109 